pine by this insect. Emphasis is placed on reduction in increment and potential volume loss related to extent of defoliation.

A study of the biology of the Mountain Pine Beetle was initiated in 1955. Severe damage by this insect has been recorded repeatedly in stands of lodgepole and western white pine.

Tentative plans have been made for a new project to be set up for 1957. This would involve the study of the occurrence, biology, and extent of damage of a root weevil, Hypomolyx sp. This insect attacks the root collar and roots of several forest trees, particularly lodgepole pine. Survey records show that the extent of damage may be more severe than hitherto realized.

Contributed by W. C. MCGuppIN

\title{
BOUNDARY MARKING
}

Boundary marking of cutting unit areas, marking of seed trees, road location delineation has, in the past, involved the use of axe blazes or tree paint. Where intensive use is being made of the forest by logging operators, trappers, hunters, and others, axe blazes at times can become most confusing. Tree paint marking involves the use of expensive materials and equipment and much time is lost in mixing paint and carrying it on the job.

A plastic tape has been used successfully by the Forestry Department of North Western Pulp \& Power Limited, Hinton, Alberta, for the marking of all camp cutting areas and delineation of the cutting pattern on these camp areas. The tape is available in several colors, at a cost of 90 cents per roll, in widths of one-half inch and one inch. The plastic material is completely inert and withstands weathering admirably. No damage by animals, especially by bears and squirrels, has been experienced to date after over twelve months in use. Camp boundaries are marked by stapling strips of tape to the trees, "coming and going", with a hanmer stapler. Cutting pattern boundaries are similarly marked with strips of tape double-stapled so that a length of tape is moulded to the tree facing into the "cut" area and a staple is placed near each end of the strip of tape. Three rolls of tape are sufficient to allow a two-man crew to delineate four miles of boundary. Equipment required for such a crew is a staple hammer and a box of staples, all of which can be carried in a cruising vest.

There are other uses for this tape. Road locations can be marked in the bush; seed trees can also be easily delineated. Confusion is eliminated by the use of standard colors for specific needs: e.g. orange for boundaries; blue for road locations; yellow for seed trees, etc.

It has been found that the tape cannot be used at extremely low temperatures, below $20^{\circ} \mathrm{F}$, as it becomes brittle and disintegrates easily.

Contributed by J. D. CEARK

\section{Newfoundland Section is Formed}

The Organizational Meeting of the Newfoundland Section of the Canadian Institute of Forestry was held in St. John's in the late afternoon of November 28th, 1956.

Thirteen members were present representing Bowater's Newfoundland Pulp and Paper Mills, Limited, the Anglo-Newfoundland Development Com- 